\title{
Time efficient laser modification of steel surfaces for advanced bonding in hybrid materials
}

\author{
D. Voswinkel ${ }^{1} \cdot$ D. Kloidt ${ }^{1} \cdot$ O. Grydin ${ }^{1}$ (1) $\cdot$ M. Schaper ${ }^{1}$
}

Received: 29 July 2020 / Accepted: 24 November 2020 / Published online: 23 December 2020

(c) The Author(s) 2020

\begin{abstract}
Laser surface treatment of metals is one option to improve their properties for adhesive bonding. In this paper, a pulsed YVO4 Laser source with a wavelength of $1064 \mathrm{~nm}$ and a maximum power of $25 \mathrm{~W}$ was utilized to increase the surface area of the steel HCT490X in order to improve its bonding properties with a carbon fibre reinforced polymer (CFRP). Investigated was the influence of the scanning speed of the laser source on the bonding properties. For this purpose, the steel surfaces were ablated at a scanning speed between 1500 and $4500 \mathrm{~mm} / \mathrm{s}$. Afterwards the components were bonded with the adhesive HexBond $^{\mathrm{TM}}$ 677. After lap shear tests were carried out on the specimen, the surfaces were inspected using scanning electron microscopy (SEM). The experiments revealed that the bonding quality can be improved with a high scanning speed, even when the surface is not completely ablated.
\end{abstract}

Keywords Laser surface $\cdot$ Laser ablation $\cdot$ Fibre-metal laminates $\cdot$ Surface treatment $\cdot$ Adhesive bonding $\cdot$ Hybrid structures

\section{Introduction}

To minimize the energy consumption and $\mathrm{CO}_{2}$ emissions of vehicles, mass reduction is an omnipresent objective in the automotive industry. A promising approach to reducing mass while simultaneously ensuring the required safety relevant strength properties is the use of hybrid materials like fibre-metal laminates (FML) or steel structures partially reinforced with carbon fibre reinforced polymers (CFRP) in modern car structures. This is made possible by combining the best features of metals and fibre-reinforced matrix materials, e.g. the impact resistance of metals with the high stiffness and lightweight properties of compound materials $[1,2]$.

Hybrid structures are manufactured by adhesive bonding, which offers several advantages over mechanical joining, such as even force transmission compared to riveted or screwed hybrid structures with stress concentrations at the joining points [3]. In addition, the joining of dissimilar materials can lead to contact corrosion. This can be prevented by

O. Grydin

grydin@1wk.upb.de

1 Lehrstuhl Für Werkstoffkunde (Materials Science), Paderborn University, Warburger Straße 100, 33098 Paderborn, Germany using an adhesive, which acts as a galvanic isolator between the materials [4]. Furthermore, adhesive bonding has a higher potential for light weight structures [5].

In order to achieve a solid adhesive bond, the surface condition of the joints is of essential importance [6]. Contaminants such as oil deposits have to be removed by degreasing [7]. Another way to improve direct adhesion and promote mechanical interlocking between the joints is to increase the surface area by various techniques such as anodising, sand blasting or laser ablation $[1,4,8]$. Among these, laser ablation stands out for its high precision, efficiency, environmental friendliness and simple implementation as an automated method in industrial applications [9]. In contrast to chemical processes, laser ablation can also be used for local surface treatments, which is beneficial for strengthening or repairing of metallic structures with CFRP patches [10].

Pulsed laser sources are common in surface treatment and micromachining applications $[9,11]$. The pulse energy $\mathrm{P}_{\mathrm{e}}$ and the pulse power $\mathrm{P}_{\mathrm{p}}$ determine the amount of machined volume [11], i.e. they can also influence the intensity of the surface treatment. Both depend on the pulse frequency $f$ as shown in formulas 1 and 2 [11]. By increasing the pulse frequency $f$, the pulse energy $\mathrm{P}_{\mathrm{e}}$ and the pulse power $\mathrm{P}_{\mathrm{p}}$ decrease. 
$\mathrm{P}_{e}=\frac{\mathrm{P}_{a}}{f}$

$\mathrm{P}_{p}=\frac{\mathrm{P}_{e}}{\mathrm{D}}=\frac{\mathrm{P}_{a}}{f . D}$

Feng et al. [6] showed that laser modification of steel changes the surface morphology on a macro scale, which results in a higher bond strength in adhesive joints compared to steel surfaces without laser modification. Huang et al. [8] attributed the enhanced adhesion strength to mechanical interlocking between the joints caused by the periodic microstructure surface structure at the interface.

The energy of a laser pulse is absorbed by the metallic material, which causes the material to melt until it reaches the vaporization temperature [9]. This leads to the formation of a plasma plume, which generates a high internal pressure, also known as recoil pressure [12]. Under this pressure, the molten metallic material is ejected from the plasma plume and falls back to the material surface where it forms a layer of re-solidified debris. The laser forms a crater which captures the remaining molten material [9]. The emerged craters and re-solidified debris build the laser structured surface morphology. Kurtovic et al. showed that laser treatment of metallic materials modifies the surface even on the nano scale [13]. A thin porous oxide layer is formed, which significantly improves wettability and thus additionally increases the surface properties for adhesive bonding [14].

When it comes to the manufacturing of hybrid components, e.g. semi-finished FML products, the surface preparation should be maintained as efficient as possible, which is controlled by travel speed of the laser beam over the metallic surface, or scan speed.

So far, laser ablation to improve bonding properties has been implemented with scanning speeds far below the technical possibilities. Feng et al. worked with a scanning speed of $100 \mathrm{~mm} / \mathrm{s}$ [6], Rotella et al. prepared the steel substrates for their lap shear tests at $500 \mathrm{~mm} / \mathrm{s}$ [7], and Zinn et al. at $800 \mathrm{~mm} / \mathrm{s}$ [4]. However, laser systems are able to operate at much higher scanning speeds. The maximum scanning speed of the laser system used for this work is $8000 \mathrm{~mm} / \mathrm{s}$ [15], which implies a great potential regarding the efficiency of laser ablation. Rotella et al. showed that higher laser scanning speeds lead to a lower degree of surface modification due to the shorter interaction time between the laser beam and the surface [7]. In another study, Feng et al. found that a higher number of craters or dimples per square millimetre induced by the laser beam increases the shear strength of the adhesive bond [16]. At high scanning speeds, however, fewer craters are formed, which means that the scanning speed cannot be increased at will. Therefore, the purpose of this study is to achieve improved bonding properties of metallic surfaces that were laser treated with a high efficiency, as well as to find correlations between the process conditions of the laser treatment, the ratio between laser treated and untreated surface and the tensile shear strength of bonded joints.

\section{Experimental procedure}

\subsection{Material}

The zinc coated dual-phase steel HCT490X [16] with a thickness of $0.55 \mathrm{~mm}$ was used as the steel substrate for the laser surface treatment. This material is mainly utilised in the automotive industry because of its good lightweight and safety properties. The second component of the hybrid material is a $0.3 \mathrm{~mm}$ thick unidirectional prepreg, the SIGRAPREG C U230-0-/NF-E320 [17]. The adhesive HexBond ${ }^{\mathrm{TM}} 677$ [18] was applied to bond the components to a hybrid material. It is coated with a thin layer of glass fibres, which serve the purpose of separating the bonding partners to avoid contact corrosion [4].

\subsection{Equipment}

A Q-switched pulsed $\mathrm{YVO}_{4}$ laser (MD-X1520C) was used to perform the laser surface treatment. Its specific properties are shown in Table 1 [15].

\subsection{Laser surface treatment}

First, the laser parameters for the surface treatment had to be determined, which is why a parameter study was carried out. The laser system was used to create a parameter matrix on the surface of the steel substrate, which is shown in Fig. 1. The laser ablation was conducted in pulsed mode with a constant output power of $25 \mathrm{~W}$. The varied parameters were the pulse frequency $f(15 \mathrm{kHz}, 30 \mathrm{kHz}, 45 \mathrm{kHz})$ and the scan speed $v(1500 \mathrm{~mm} / \mathrm{s}, 3000 \mathrm{~mm} / \mathrm{s}, 4500 \mathrm{~mm} / \mathrm{s})$.

Then, the laser treated areas of the matrix were examined by scanning electron microscopy (SEM). The secondary electron detector (SE2) with an acceleration voltage of $20 \mathrm{kV}$ was used for the overview images, and the InLens detector with an acceleration voltage of $3 \mathrm{kV}$ for the closeups. These investigations were designed to determine the

Table 1 Specifications of the laser system MD-X1520C [15]

\begin{tabular}{ll}
\hline Wavelength $\lambda$ & $1060 \mathrm{~nm}$ \\
Average power $\mathrm{P}_{\mathrm{a}}$ & Max. $25 \mathrm{~W}$ \\
pulse frequency $f$ & $1-400 \mathrm{kHz}$ \\
Scan speed $v$ & Max. $8000 \mathrm{~mm} / \mathrm{s}$ \\
Pulse duration $D$ & $4 \mathrm{~ns}$ \\
Spot Size $d$ & $5 \mu \mathrm{m}$ \\
\hline
\end{tabular}




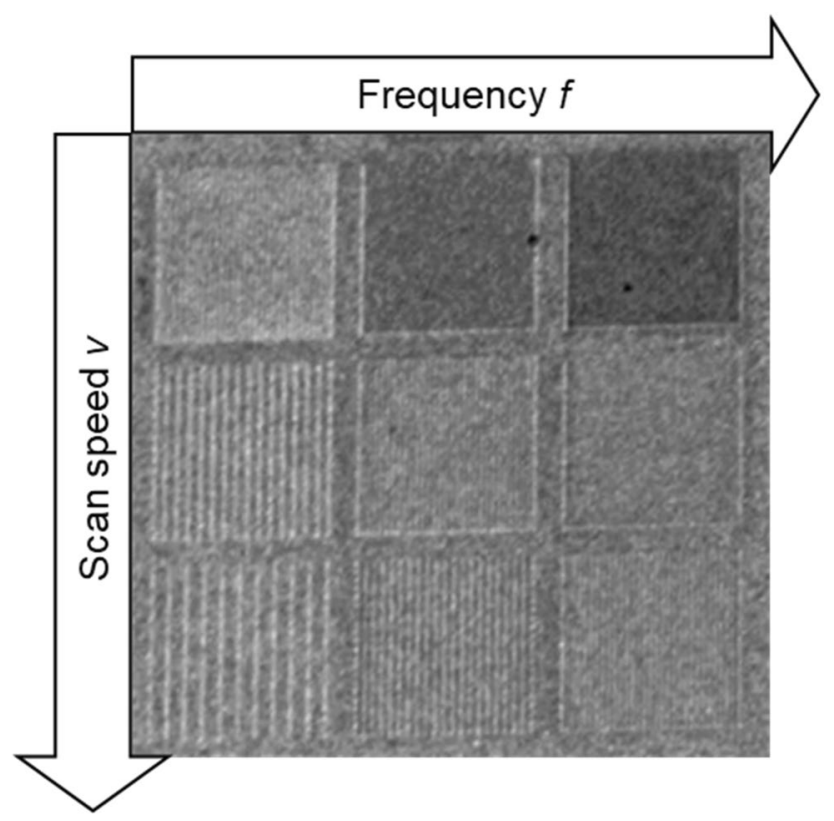

Fig. 1 Parameter matrix of the laser treatment

increase in surface area to ensure that the adhesion properties of the steel surface are improved for each pair of parameters. Figure 2 shows a laser spot created by a single laser pulse and a close up of the surface within the spot. The expansion of the surface could be verified for each pair of parameters.

To determine the influence of the laser treatment on the chemical composition of the surface, i.e. whether a nanoporous zinc oxide layer was created, both surface conditions (laser treated and untreated) were analysed in the SEM by means of energy dispersive X-ray spectroscopy (EDX).

Figure 3 illustrates the laser treatment procedure. The distance between two laser spots in y-direction can be defined by the laser system itself and remains constant during the process. The distance in scanning direction or in $\mathrm{x}$-direction is determined by the scanning speed $v$ and the pulse frequency $f$. Consequently, there are different ratios between laser treated and untreated surface area for each parameter

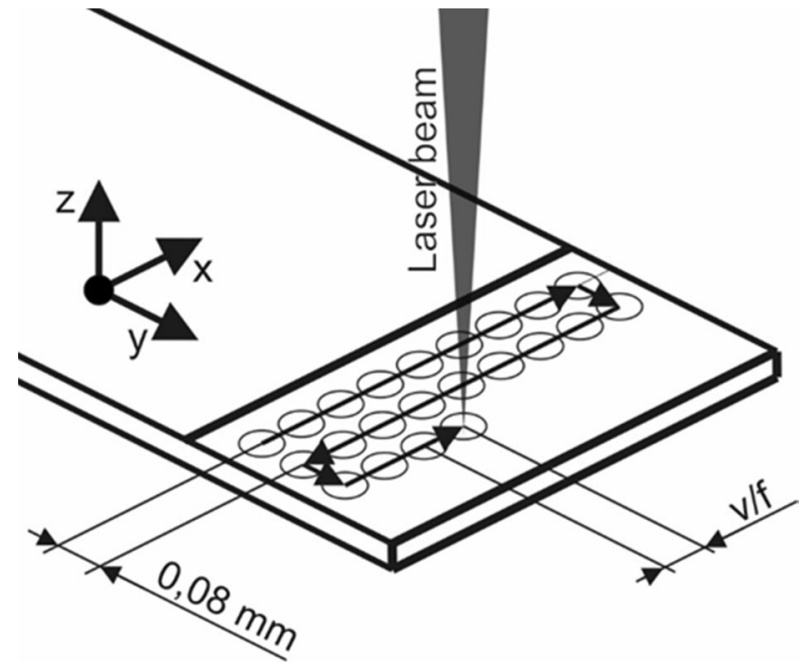

Fig. 3 Procedure of the laser treatment

pair. The direct influence of the scanning speed on the distance between two laser spots is shown in Fig. 4. For each parameter pair, the ratio between laser treated and untreated surface was determined by means of three SEM images each and then defined as spot density $s d$.

\subsection{Preparation of the samples and lap shear tests}

Subsequently, the samples were prepared for the lap shear tests. The steel sheets were cut out to $100 \mathrm{~mm} \times 20 \mathrm{~mm}$ by means of a plate shear. The CFRP prepreg stripes were cut to the same dimensions with a box cutter. One sample consists of a steel sheet and 2 CFRP prepreg strips (Fig. 5). The arrangement of two CFRP strips prevents a bending of the sample during the lap shear tests. The fibres of the CFRP strips were arranged in the shear force direction of the sample. The areas of the steel sheets to be bonded were degreased and then laser treated with the specific parameters from both sides over the entire width.

As the next step the components had to be bonded adhesively with an overlapping length of $6,5 \mathrm{~mm}$. This was
Fig. 2 Surface expansion within a single laser spot, $f=30 \mathrm{kHz}$, $v=3000 \mathrm{~mm} / \mathrm{s}$

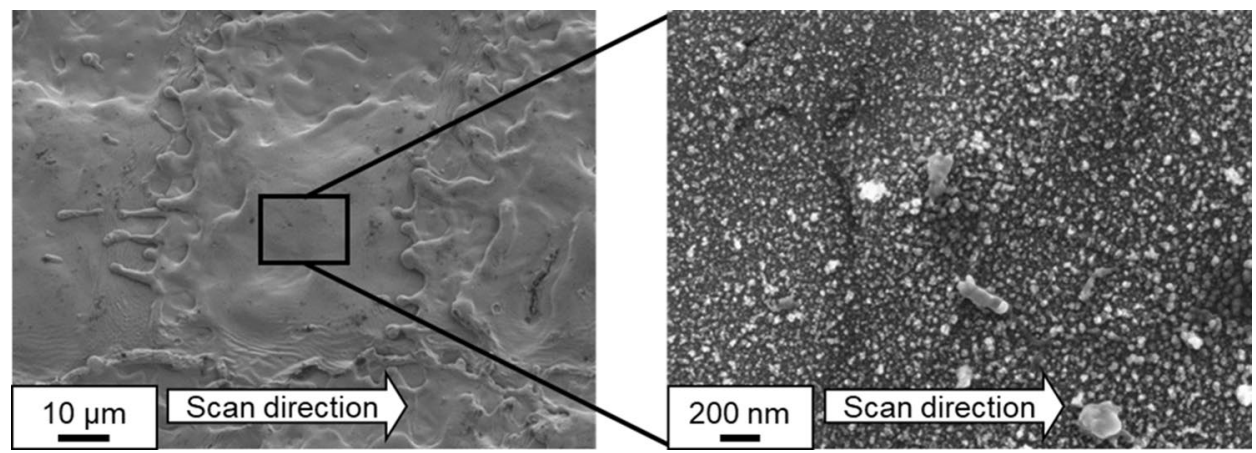


Fig. 4 Direct influence of the scanning speed on the distance between two laser spots, a $v=1500 \mathrm{~mm} / \mathrm{s}, f=15 \mathrm{kHz} \mathbf{b}$ $v=3000 \mathrm{~mm} / \mathrm{s}, f=15 \mathrm{kHz} \mathbf{c}$ $v=4500 \mathrm{~mm} / \mathrm{s}, f=15 \mathrm{kHz}$
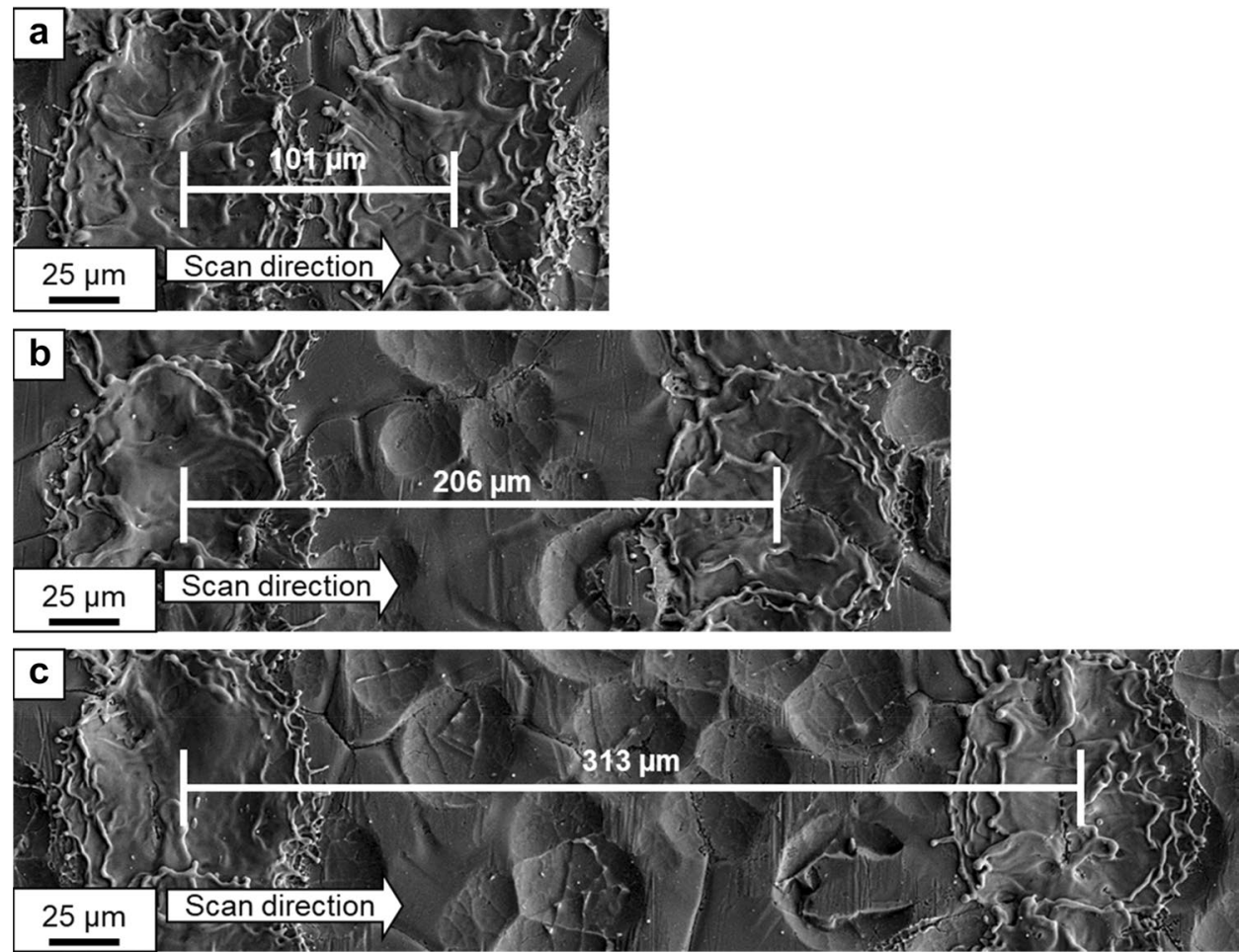

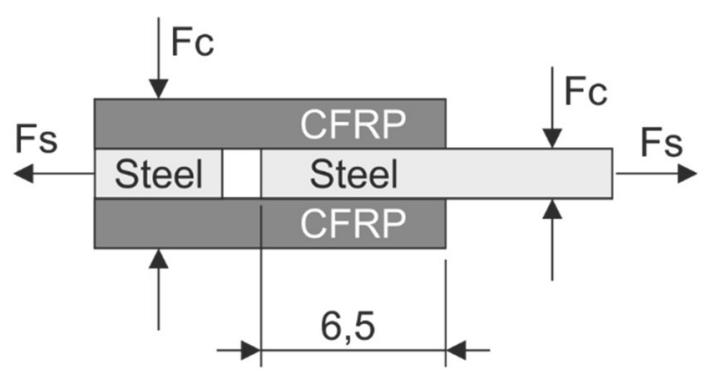

Fig. 5 Composition of a lap shear test sample, $\mathrm{F}_{\mathrm{S}}$ : shear force, $\mathrm{F}_{\mathrm{C}}$ : clamping force

done with a specific apparatus at a bonding temperature of $150{ }^{\circ} \mathrm{C}$ with a pressure of approximately $350 \mathrm{kPa}$ for 4 min. CFRP prepregs and adhesive were cured together. Five samples were prepared for each parameter pair, and an additional five were manufactured as reference without any laser treatment.

The lap shear tests were executed on a servo hydraulic testing machine (MTS Landmark). Figure 5 illustrates the areas where the clamping force $\left(\mathrm{F}_{\mathrm{C}}\right)$ and shear force $\left(\mathrm{F}_{\mathrm{S}}\right)$ were applied. The shear force was perpendicular to the scanning direction. The test speed was $1 \mathrm{~mm} / \mathrm{min}$ until fracture or the maximum shear force was reached. Subsequently, the shear strength was calculated by means of the maximum force and the bonded area.

The fracture surfaces of the lap shear samples were examined in the SEM with the SE2 detector and an acceleration
Table 2 Chemical composition of the laser treated and untreated surface

\begin{tabular}{lll}
\hline Element & \multicolumn{2}{l}{ Weight $\%$} \\
\cline { 2 - 3 } & Laser treated & Untreated \\
\hline $\mathrm{Zn}$ & 98.07 & 97.82 \\
$\mathrm{O}$ & 0.90 & 1.07 \\
$\mathrm{Fe}$ & 0.74 & 0.81 \\
$\mathrm{Mn}$ & 0.28 & 0.29 \\
\hline
\end{tabular}

voltage of $20 \mathrm{kV}$, focussing on the adhesive or cohesive failure behaviour at the treated and untreated areas of the steel surface.

\section{Results}

\subsection{Chemical composition of the surface}

Table 2 shows the average of three EDX scans of the atomic weight percentage of the laser treated and untreated surface. There are only slight differences between the surface states.

\subsection{Spot density}

The spot density in decimal representation for each parameter pair is shown in Fig. 6. It can be seen that the density decreases with increasing scanning speed. When a pulse 


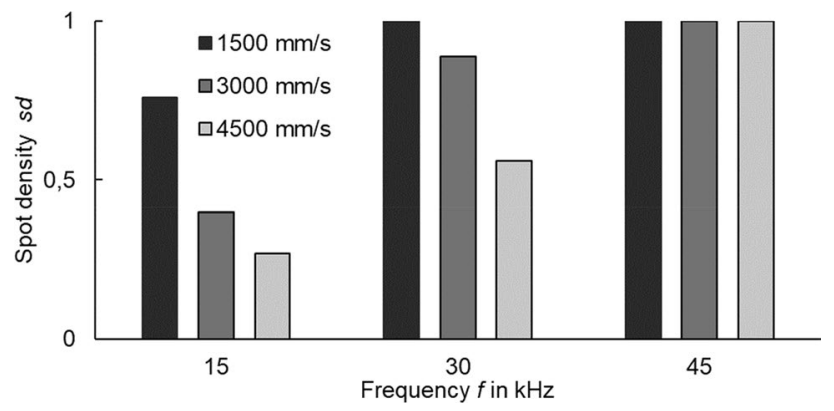

Fig. 6 Spot density $s d$ referred to scan speed $v$ and pulse frequency $f$

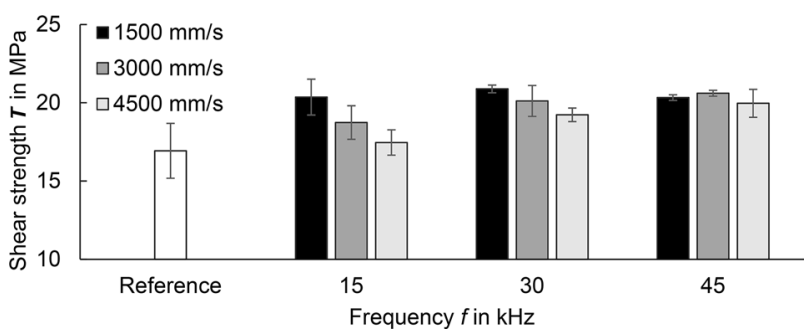

Fig. 7 Average shear strength referred to scan speed $v$ and pulse frequency $f$

frequency of $45 \mathrm{kHz}$ is reached, the spot density will remain 1. At this point, saturation of the spot density is achieved. The pulse frequency compensates a rising scan speed in relation to the spot density.

\subsection{Lap shear tests}

The results of the lap shear tests are illustrated in Fig. 7. The average shear strength of the laser treated samples is higher than that of the untreated samples. However, the average shear strength of the reference shows a relatively high standard deviation. The diagram shows that scanning speed and pulse frequency have a high influence on the shear strength. At $15 \mathrm{kHz}$ the scanning speed is the decisive parameter, the shear strength decreases with increasing scanning speed. As soon as the pulse frequency is increased, however, this effect diminishes until it is almost completely insignificant at a pulse frequency of $45 \mathrm{kHz}$.

\subsection{Fractography}

Figure 8 shows fracture surfaces with different spot densities after the lap shear tests. A single laser spot can be seen in Fig. 8a. The dark areas in Fig. 8b, c are residues of the applied adhesive, primarily located on the laser spots. The residues on the surface seen in Fig. 8d are distributed randomly. Moreover, glass fibres of the adhesive are visible. Figure 8e shows a fractured surface without previous laser treatment, which is also partially covered with remnants of the adhesive.

\section{Discussion}

There are almost no differences in chemical composition between the laser treated and untreated surface. The relatively small deviations are likely due to the accuracy of the measuring method. It should be noted that in an EDX, the chemical composition is not measured directly on the surface, but in an area just below it due to the penetration depth of the electron beam [19]. Thus, if a nanoporous zinc oxide layer was generated during laser ablation within the spots, it would probably be too thin to be verified by such a scan. To increase the depth of the oxide layer, a higher pulse energy is required [20]. However, it is more likely that the rough surface texture within a single laser spot, as shown in Fig. 2, is induced by the previously described resolidified debris than by the formation of a zinc oxide layer. This significantly increases the surface area in addition to the surface morphology caused by the laser spot formation.

When working with an increased scanning speed of the laser beam, the expansion of the surface is less pronounced due to a smaller number of laser spots. This means that the more laser spots there are in relation to the surface, the larger the surface itself and the better the bonding properties. This correlation is clearly shown in Fig. 9. It is evident that a higher density of laser spots on the steel surface leads to a higher shear strength of the bonded area. The relationship between spot density and shear strength is nearly linear, the coefficient of determination is approximately 0.92 .

The evaluation of the spot density shows that, if a high scanning speed is required, the increasing distance between two laser spots shown in Fig. 4 can be compensated by raising the pulse frequency. With a pulse frequency of $45 \mathrm{kHz}$ the surface area can be completely processed by the laser beam even at a high scanning speed of $4500 \mathrm{~mm} / \mathrm{s}$, which increases the shear strength by $15 \%$ compared to the untreated surface. However, as the pulse frequency $f$ rises, the pulse power $\mathrm{P}_{\mathrm{p}}$ simultaneously decreases (see Eq. 2). Leone et al. [11] argued that once the pulse power falls below a certain limit, the laser ablation process becomes unstable. Thus, the possibility to work with a high scanning speed at high frequencies to improve the bonding properties is limited. In the range of lower pulse frequencies, in this case $15 \mathrm{kHz}$, the variation of the scanning speed has a high influence on the shear strength.

Semi-finished FML products are often further processed by deep drawing, for example car body parts like cross 
Fig. 8 Fractured surfaces of joints produced using steel substrates with different spot densities, $\mathbf{a}$ and $\mathbf{b} s d=0.27 \mathbf{c}$ $s d=0.40 \mathrm{~d} s d=1$ e reference, 1: Residues of the adhesive, 2 : Laser spot surface, 3: Untreated surface, 4: Glass fibre
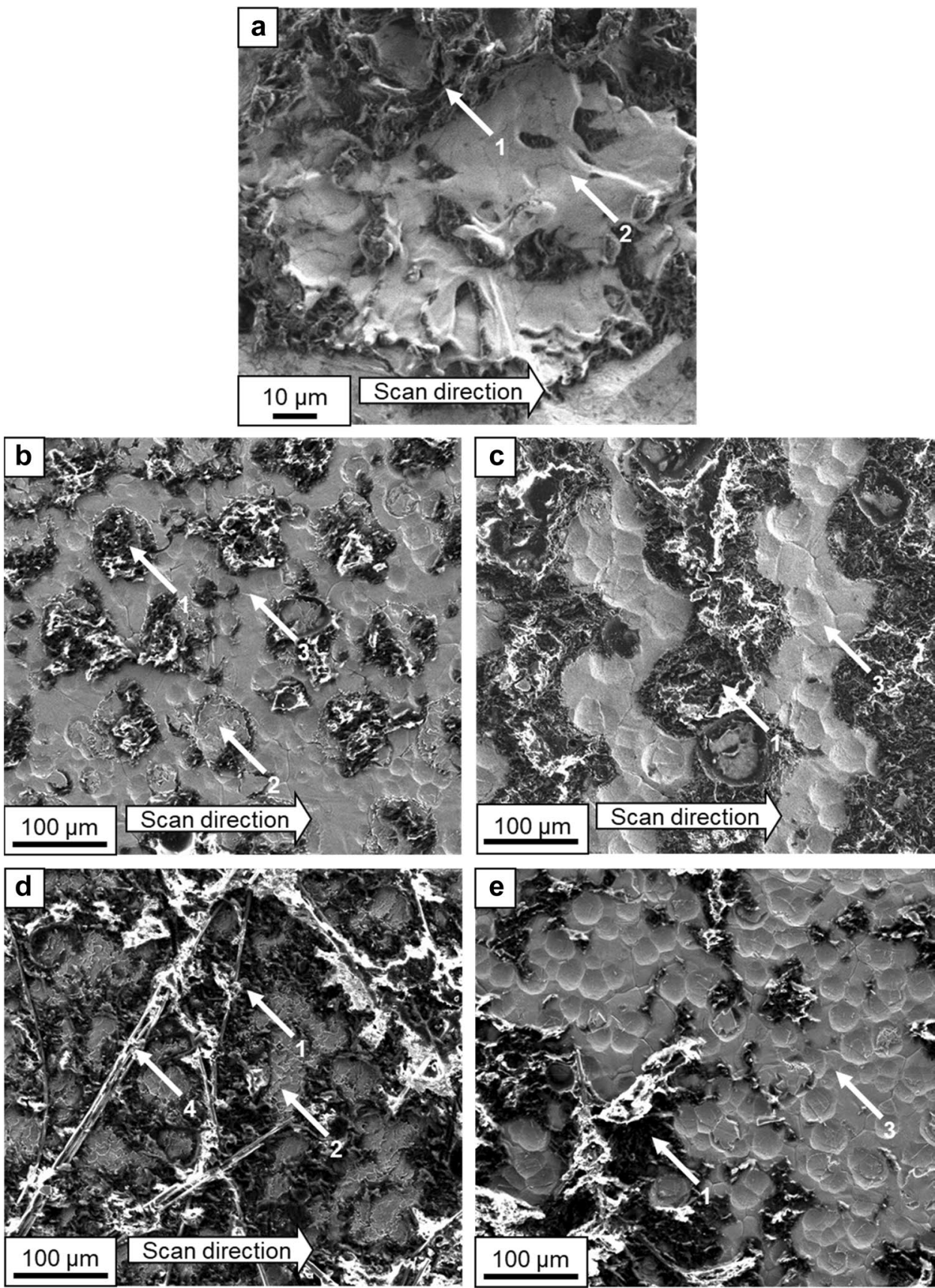

members or the B-pillar [21]. During deep drawing, different stress conditions and relative movements between the laminates occur [21]. Consequently, the maximum bond strength between the laminates is not ideal for every area of the FML. Hence, the scan speed variation can be used for the targeted generation of reproducible graded surface morphologies on the steel surface in order to optimize further manufacturing processes.

The SEM images (Fig. 8) reveal a primary cohesive failure behaviour on the laser spots, which is evidently the preferred fracture mode as it indicates that the joint strength has reached or exceeded the strength of the adhesive [9]. This is attributed to the increased surface area within the laser spots [6]. At a higher spot density, more adhesive residues remain on the surface, which further underlines the conclusion of Fig. 9. The glass fibres seen on Fig. 8d obviously come from the used adhesive, as described in 2.1. While residues of the adhesive are also visible on the untreated surface (Fig. 8e), their arrangement appears random in contrast to laser-treated surfaces. This would reduce the reproducibility and thus the possibility to grade the bonding properties of the steel surface. This is also confirmed by the high standard deviation of 


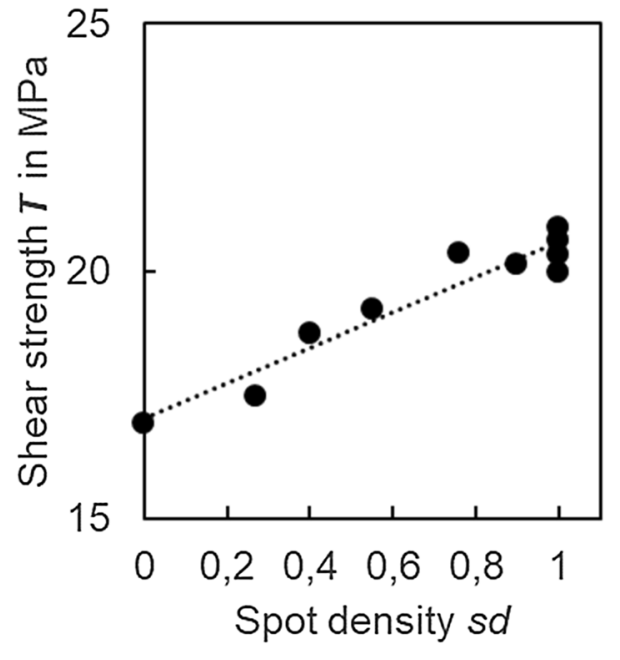

Fig. 9 Correlation between spot density and shear strength

the shear strength of untreated steel surfaces in hybrid materials, see Fig. 7.

\section{Conclusions}

The influence of scanning speeds between $1500 \mathrm{~mm} / \mathrm{s}$ and $4500 \mathrm{~mm} / \mathrm{s}$ in laser surface treatments on the bonding properties of steel surfaces in hybrid materials was investigated.

- Laser surface treatment increases the surface area through the newly created surface morphology and the rough nanoscopic texture within a single laser spot, which is due to re-solidified debris falling back onto the surface.

- Cohesive failure behaviour was mainly observed at the laser spots, indicating the better bonding properties of laser treated surfaces.

- The amount of laser spots on the surface determines the bonding properties, and was defined as spot density $s d$. The spot density increases with the pulse frequency and decreases with the scanning speed.

- Working with a high pulse frequency allows the application of high scanning speeds, which significantly improves the efficiency of the laser surface treatment. Compared to the reference, the shear strength was increased by $15 \%$ at a scanning speed of $4500 \mathrm{~mm} / \mathrm{s}$ and by $18 \%$ at $3000 \mathrm{~mm} / \mathrm{s}$. This is significantly more time efficient than in earlier studies.

- By varying the scanning speed at low frequencies, it is possible to accurately grade the bonding properties of steel surfaces in order to optimize the surface condition for further manufacturing processes of hybrid semifinished products.

Acknowledgement The authors gratefully acknowledge the financial support from the European Regional Development Fund (ERDF) and the state of North Rhine-Westphalia (NRW) within the project HyOpt.

Funding Open Access funding enabled and organized by Projekt DEAL. This research was supported by the European Regional Development Fund (ERDF).

Code availability Not applicable.

\section{Compliance with ethical standards}

Conflict of interest The authors declare that they have no conflict of interest.

Availability of data and material The data which was used for this paper is archived on the servers of the Chair of Materials Science of the Paderborn University and can be sent if demanded.

Open Access This article is licensed under a Creative Commons Attribution 4.0 International License, which permits use, sharing, adaptation, distribution and reproduction in any medium or format, as long as you give appropriate credit to the original author(s) and the source, provide a link to the Creative Commons licence, and indicate if changes were made. The images or other third party material in this article are included in the article's Creative Commons licence, unless indicated otherwise in a credit line to the material. If material is not included in the article's Creative Commons licence and your intended use is not permitted by statutory regulation or exceeds the permitted use, you will need to obtain permission directly from the copyright holder. To view a copy of this licence, visit http://creativecommons.org/licenses/by/4.0/.

\section{References}

1. Sinmazçelik T, Avcu E, Bora MÖ et al (2011) A review: fibre metal laminates, background, bonding types and applied test methods. Mater Des 32:3671-3685. https://doi.org/10.1016/j. matdes.2011.03.011

2. Kavitha K, Vijayan R, Sathishkumar T (2020) Fibre-metal laminates: a review of reinforcement and formability characteristics. Mater Today: Proc 22:601-605. https://doi.org/10.1016/j.matpr .2019 .08 .232

3. Altmeyer J, Suhuddin UFH, dos Santos JF et al (2015) Microstructure and mechanical performance of metal-composite hybrid joints produced by FricRiveting. Compos B Eng 81:130-140. https://doi.org/10.1016/j.compositesb.2015.06.015

4. Zinn C, Bobbert M, Dammann C et al (2018) Shear strength and failure behaviour of laser nano-structured and conventionally pre-treated interfaces in intrinsically manufactured CFRP-steel hybrids. Compos B Eng 151:173-185. https://doi.org/10.1016/j. compositesb.2018.05.030

5. Arenas JM, Alía C, Narbón JJ et al (2013) Considerations for the industrial application of structural adhesive joints in the aluminium-composite material bonding. Compos B Eng 44:417-423. https://doi.org/10.1016/j.compositesb.2012.04.026 
6. Feng Z, Zhao H, Tan C et al (2019) Effect of laser texturing on the surface characteristics and bonding property of $30 \mathrm{CrMnSiA}$ steel adhesive joints. J Manuf Process 47:219-228. https://doi. org/10.1016/j.jmapro.2019.09.046

7. Rotella G, Alfano M, Schiefer T et al (2015) Enhancement of static strength and long term durability of steel/epoxy joints through a fiber laser surface pre-treatment. Int J Adhes Adhes 63:87-95. https://doi.org/10.1016/j.ijadhadh.2015.08.009

8. Huang B, Sun L, Li L et al (2017) Experimental investigation of the strength of polymer-steel direct adhesion (PSDA) joints with micro-structures ablated by laser. J Mater Process Technol 249:407-414. https://doi.org/10.1016/j.jmatprotec.2017.06.031

9. Min J, Wan H, Carlson BE et al (2020) Application of laser ablation in adhesive bonding of metallic materials: a review. Opt Laser Technol 128:106188. https://doi.org/10.1016/j.optla stec.2020.106188

10. $\mathrm{Ke} \mathrm{L}, \mathrm{Li} \mathrm{C}, \mathrm{He} \mathrm{J}$ et al (2020) Enhancing fatigue performance of damaged metallic structures by bonded CFRP patches considering temperature effects. Mater Des 192:108731. https://doi. org/10.1016/j.matdes.2020.108731

11. Leone C, Genna S, Tagliaferri F et al (2016) Experimental investigation on laser milling of aluminium oxide using a $30 \mathrm{~W}$ Q-switched Yb:YAG fiber laser. Opt Laser Technol 76:127-137. https://doi.org/10.1016/j.optlastec.2015.08.005

12. Semak V, Matsuanawa A (1997) The role of recoil pressure in energy balance during laser materials processing. J Phys D Appl Phys 30:2541-2552

13. Kurtovic A, Brandl E, Mertens T et al (2013) Laser induced surface nano-structuring of Ti-6Al-4V for adhesive bonding. Int J Adhes Adhes 45:112-117. https://doi.org/10.1016/j.ijadh adh.2013.05.004

14. Baburaj EG, Starikov D, Evans J et al (2007) Enhancement of adhesive joint strength by laser surface modification. Int
J Adhes Adhes 27:268-276. https://doi.org/10.1016/j.ijadh adh.2006.05.004

15. Keyence 3-Axis Hybrid Laser Marker specifications. https://www. keyence.de/products/marker/laser-marker/md-x1000_1500/model s/md-x $1520 \mathrm{c} /$

16. thyssenkrupp steel DP-W® und DP-K®Produktinformation für Dualphasen-Stähle. https://www.thyssenkrupp-steel.com/media/ content_1/publikationen/produktinformationen/dp_w_dp_k/thyss enkrupp_dp-w_dp-k_produktinformation_steel_de.pdf

17. sgl carbon SIGRAPREG® Pre-Impregnated Materials. https:// www.sglcarbon.com/en/markets-solutions/material/sigrapregpre-impregnated-materials/

18. HEXCEL HexBond ${ }^{\mathrm{TM}}$ 677Modified epoxy film adhesive. https:// www.hexcel.com/user_area/content_media/raw/HexBond_677_ DataSheet.pdf

19. Abd Mutalib M, Rahman MA, Othman MHD et al (2017) Scanning electron microscopy (SEM) and energy-dispersive X-ray (EDX) spectroscopy. In: Ismail AF, Oatley-Radcliffe D, Hilal N et al (eds) Membrane characterization. Elsevier, Amsterdam, pp 161-179

20. Alfano M, Pini S, Chiodo G et al (2014) Surface patterning of metal substrates through low power laser ablation for enhanced adhesive bonding. J Adhes 90:384-400. https://doi. org/10.1080/00218464.2013.871538

21. Heggemann T, Homberg W (2019) Deep drawing of fiber metal laminates for automotive lightweight structures. Compos Struct 216:53-57. https://doi.org/10.1016/j.compstruct.2019.02.047

Publisher's Note Springer Nature remains neutral with regard to jurisdictional claims in published maps and institutional affiliations. 